\title{
Bandwidth enhancement of rectangular microstrip patch antenna using slots
}

\author{
E.Sivakumar ${ }^{1}$, Srinivasa Rao $\mathrm{O}^{2}$, A.V.M.Manikandan ${ }^{3}$ \\ 1(Dept of Electronics and Communication Engineering, SRM University, Chennai, India) \\ 2(Communications Systems, SRM University, Chennai, India) \\ 3(Dept of Electronics and Communication Engineering, SRM University, Chennai, India)
}

\begin{abstract}
In this paper, a new design of rectangular microstrip patch antenna (RMPA) without slot, with slots and array is proposed and analyzed. The designed antenna has been simulated using HFSS software. The simulated results for return loss, radiation pattern and gain are presented and discussed. The bandwidth of proposed antenna is $2.4 \mathrm{GHz}-5.9 \mathrm{GHz}$ for VSWR(voltage standing wave ratio) $<2$ is achieved on the basis of <$10 \mathrm{~dB}$ return loss as an acceptable reference in wireless applications which cover worldwide interoperability for microwave access (WiMAX) and wireless local area network (WLAN) and other applications. Gain of 10dB is achieved for antenna array.
\end{abstract}

Keywords- Array, Microstrip antenna, WLAN, WiMAX

\section{Introduction:}

There is a huge demand for the design of antennas which can operate over multiple bands due their vital role played in wireless communication systems. In order to satisfy the WLAN recommendations at 2.4/5.2/5.8 GHz operating bands and WiMAX standard at 2.5/3.5/5.5 GHz bands, microstrip patch antennas are preferred due to their extraordinary features. Microstrip patch antennas show some important features which are low profile, light weight, low cost, simplicity and inexpensive manufacturability using modern printed circuit technology, mechanical robustness when mounted on rigid surfaces, compatibility with Microwave Monolithic designs, etc.

Selecting a particular patch shape and mode microstrip patch antennas are very versatile in terms of resonant frequency, polarization, pattern and impedance [1]. In [2], a unipolar printed couple-fed planar inverted-F antenna (PIFA) with a band-notching slit for WLAN/WiMAX applications has been demonstrated. In [3], a printed microstrip line-fed rhombus slot antenna with a pair of parasitic strips has been presented. In [4], a compact planar Ultra-Wideband (UWB) antenna with dual band-notched characteristics has been reported. In [5,6], many multiband antennas are presented but the reported designs lack achieving a dual band response with larger bandwidth to cover the whole WLAN/WiMAX bands. A multiband PIFA covering ten frequency bands has been proposed for personal wireless communication terminals in [7], but it covers only one band of WiMAX and two bands of WLAN with increased antenna size.

The main drawback of this type of coupling feed is that the antenna is not sufficient to cover all frequency bands and the fabrication is difficult due to multiple layers. The microstrip antenna fed by Co-planar Waveguide (CPW) microstrip feed line has unique characteristics such as lower radiation leakage, wider bandwidth.

The purpose of this paper is to present a new configuration of microstrip patch antenna array for WiMAX and WLAN applications. The antenna model consists of double L-slot microstrip patch antenna array. The radiating element used in this proposed antenna is copper and we prefer rectangular shape patches compared to other types since rectangular patches are the first and probably the most utilized patch conductor geometries. Initially single microstrip patch antenna is designed and the performance metrics such as radiation pattern, VSWR, return loss and gain are simulated. To increase the gain, a design of microstrip patch antenna array is also considered. The array consists of two single patches of antenna on the same substrate. The performance of a single patch antenna and double patch antenna array is compared.

\section{Antenna Design:}

The schematic configuration of the microstrip patch antenna is shown in Fig. 1. The dimensions of the radiating structures, patch width, and the feed point position are chosen according to the required frequency of operation. The radiating patch is fed by a $50 \Omega$ transmission line. The schematic configuration of the microstrip patch antenna with two slots is shown in the Fig2. The dimensions of two slots can be adjusted to radiate in the resonant frequency range. The dimensions of two slots are selected such that it should produce wider bandwidth and perfect impedance matching. Microstrip slot antennas are capable of producing omnidirectional radiation 
pattern. The effects of ground location on microstrip antenna are important considerations in designing this type of antenna. The location of the ground from the feed point determines the impedance matching. The proposed antenna is designed with a FR4 epoxy substrate with relative dielectric constant of 4.4 and loss tangent of 0.02 . The lengths of the slot are $5.7 \mathrm{~mm} 7.5 \mathrm{~mm}$ and slot width is $1 \mathrm{~mm}$. The gap between the ground plane and patch is $3 \mathrm{~mm}$. By adjusting the feed point, perfect impedance matching is obtained. The length of the patch is 19.3 $\mathrm{mm}$ and the width of the feed line is $3 \mathrm{~mm}$.

To meet the actual design requirements, i.e. operating frequency, bandwidth, radiation pattern, and some approximations are considered. The calculations are based on the transmission line model. The effective dielectric constant of the substrate is given as [1]

$$
\varepsilon_{\text {reff }}=\frac{\varepsilon_{r}+1}{2}+\frac{\varepsilon_{r}-1}{2}\left(1+12 \frac{W}{h}\right)^{0.5}
$$

The normalized extension of the length of patch is calculated by [1]

$$
\Delta L=0.412 h \frac{\left(\varepsilon_{\text {reff }}+0.3\right)\left(\frac{W}{h}+0.264\right)}{\left(\varepsilon_{\text {reff }}-0.258\right)\left(\frac{W}{h}+0.8\right)}
$$

$\mathrm{W}$ is the width of the patch and $\mathrm{H}$ is the height of the substrate. The actual length of the patch is expressed as

$$
\mathrm{L}_{\mathrm{efff}}=\mathrm{L}+2 \Delta \mathrm{L}
$$

The width and effective length of the microstrip patch are calculated by [1]

1. RMP Antenna with and without slots:

$$
\begin{gathered}
L_{e f f}=\frac{c}{2 f_{0} \sqrt{\varepsilon_{r e f f}}} \\
W=\frac{c}{2 f} \frac{\sqrt{\frac{r+1}{2}}}{\sqrt{2}}
\end{gathered}
$$

Using the above equations and iterative trials, the dimensions of the antenna is obtained. The geometrical parameters of the considered antenna design are as follows. The length of rectangular patch $\mathrm{L}=$ $19.3 \mathrm{~mm}$, width of the rectangular patch $\mathrm{W}=19.27 \mathrm{~mm}$, width of ground plane $\mathrm{GW}=10.5 \mathrm{~mm}$, length of ground plane $\mathrm{GL}=16.2 \mathrm{~mm}$. Length of the feeding is $\mathrm{FL}=19.2 \mathrm{~mm}$ and feed width is $\mathrm{FW}=3 \mathrm{~mm}$. The space between the rectangular patch and ground plane is $\mathrm{G}=3 \mathrm{~mm}$ and vertical spacing between feed-line and ground plane is $\mathrm{D}=1 \mathrm{~mm}$. Slot lengths $\mathrm{L} 1=5.7 \mathrm{~mm}, \mathrm{~L} 2=7.5 \mathrm{~mm}$ and width $\mathrm{Ws}=1 \mathrm{~mm}$

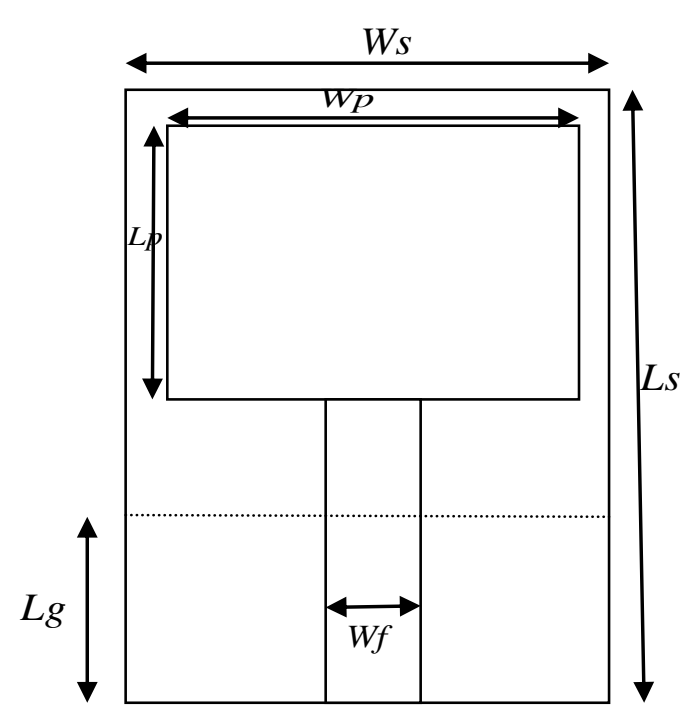

Fig1: RMP antenna design

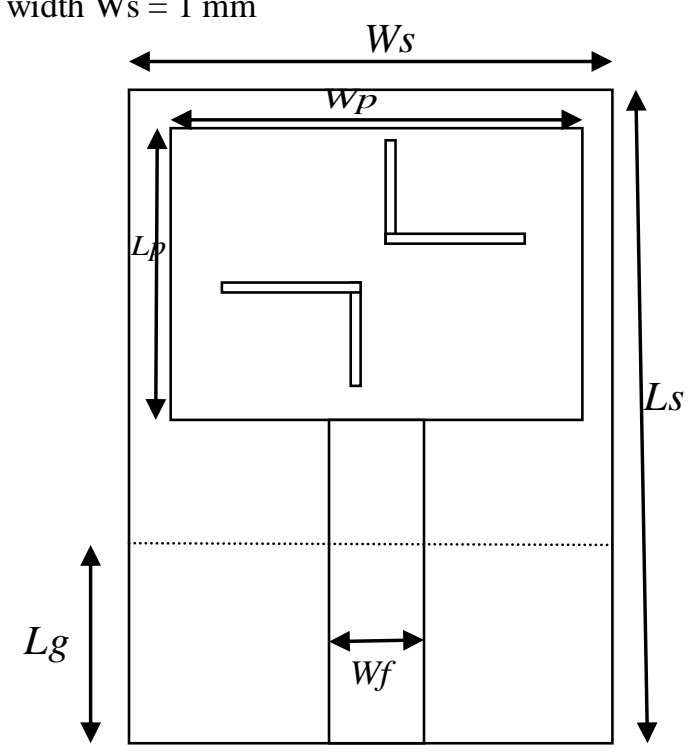

Fig2: RMPA with slots 


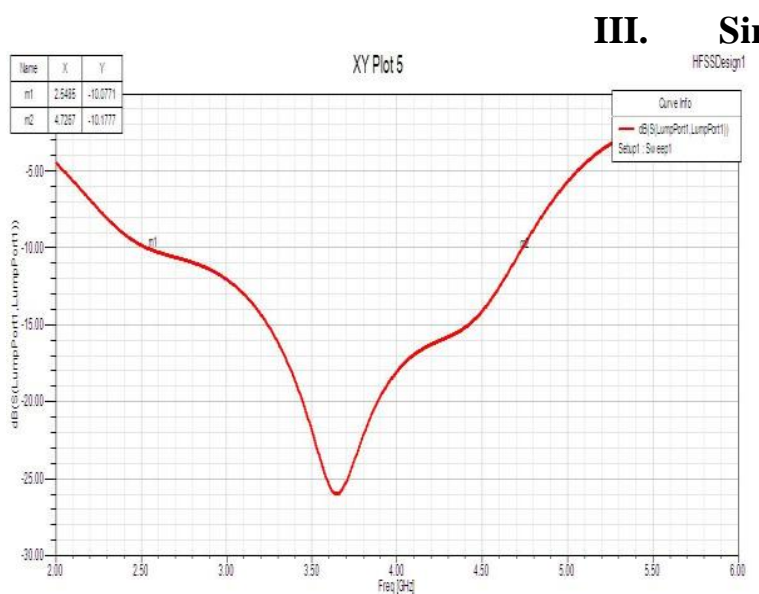

Fig3: Return loss of RMPA

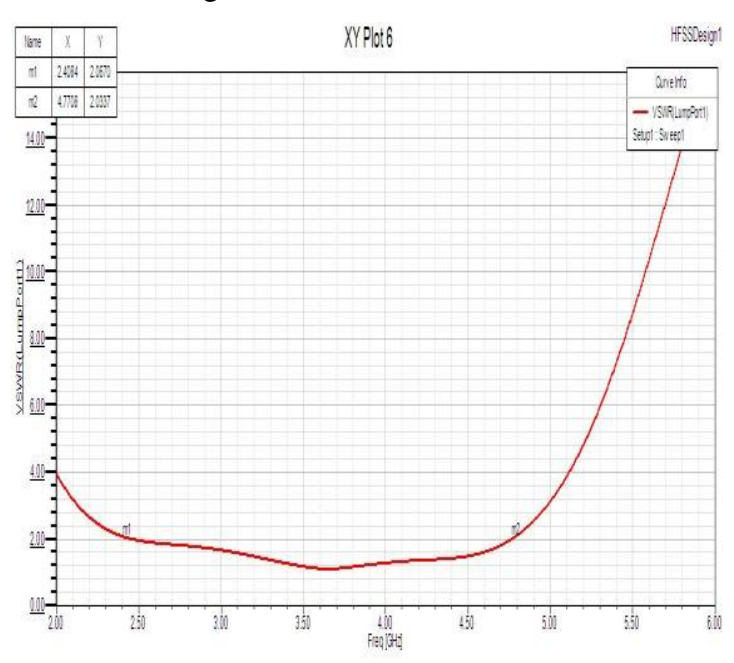

Fig5: VSWR of RMPA

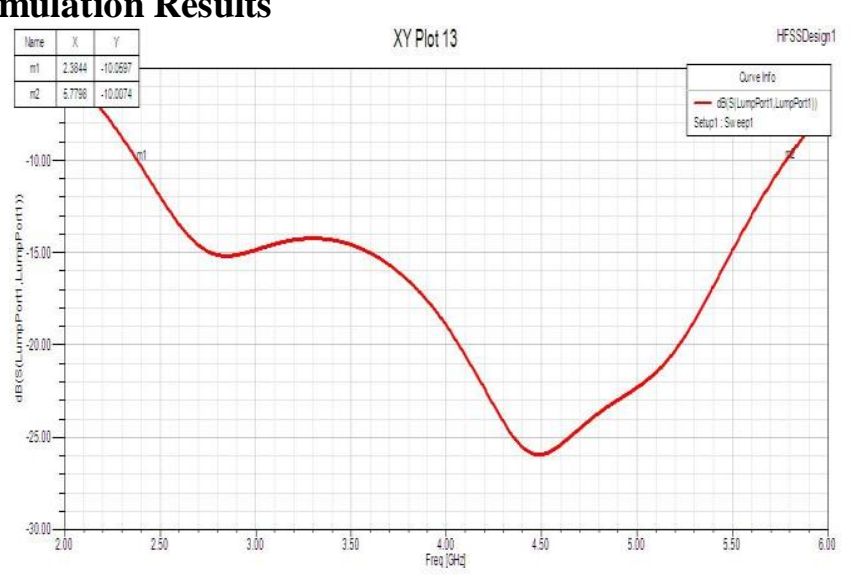

Fig4: Return loss of RMPA with slots

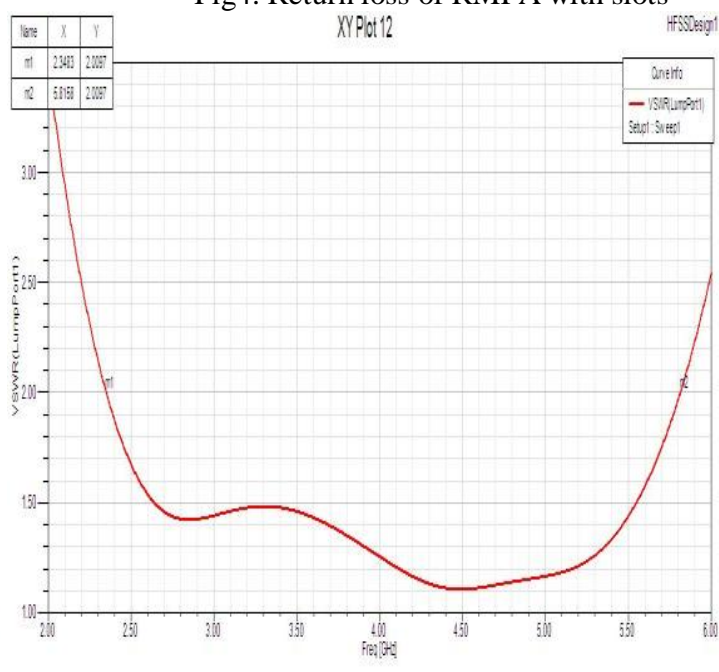

Fig6: VSWR of RMPA with slots

In this section simulations results for the return loss, VSWR, gain of the designed antennas are measured and presented. The frequency range of $2-6 \mathrm{GHz}$ is used for simulation as the WiMAX and WLAN frequency bands lies in this range. Fig. 3 shows the simulated return loss of single patch antenna. We observe that return loss for WLAN operating frequencies $2.4 \mathrm{GHz} / 5.2 \mathrm{GHz} / 5.8 \mathrm{GHz}$ are $-9 \mathrm{~dB},-4 \mathrm{~dB},-3 \mathrm{~dB}$ respectively and for WiMAX operating bands $2.5 \mathrm{GHz} / 3.5 \mathrm{GHz} / 5.5 \mathrm{GHz}$ are-9dB, $-19 \mathrm{~dB},-3 \mathrm{~dB}$ respectively. Fig. 4 shows the simulated return loss of patch antenna with slots. It is observed that return loss for WLAN operating frequencies $2.4 \mathrm{GHz} / 5.2 \mathrm{GHz} / 5.8 \mathrm{GHz}$ are $-9 \mathrm{~dB},-22 \mathrm{~dB},-13 \mathrm{~dB}$ respectively and for WiMAX operating bands 2.5 GHz/3.5 GHz/5.5 GHz are $-10 \mathrm{~dB},-20 \mathrm{~dB},-15 \mathrm{~dB}$ respectively. The return loss below $-10 \mathrm{~dB}$ is sufficient for radiation.

Therefore, from the simulation results we conclude that the proposed antenna exhibits wideband impedance bandwidth the design is simulated using Ansoft HFSS. It is observed that the measured and simulated results show good agreement with each other. Fig5 shows the VSWR of single patch antenna. It is observed that VSWR of single patch antenna for WLAN operating frequencies $2.4 \mathrm{GHz} / 5.2 \mathrm{GHz} / 5.8 \mathrm{GHz}$ are 2 , 4, 10 respectively and for WiMAX operating bands $2.5 \mathrm{GHz} / 3.5 \mathrm{GHz} / 5.5 \mathrm{GHz}$ are 2, 1.7, 9respectively and Fig. 6 shows the VSWR of patch antenna with slots. It is observed that VSWR of patch antenna with slots for WLAN operating frequencies $2.4 \mathrm{GHz} / 5.2 \mathrm{GHz} / 5.8 \mathrm{GHz}$ are 2, 1.2, 2 respectively and for WiMAX operating bands $2.5 \mathrm{GHz} / 3.5 \mathrm{GHz} / 5.5 \mathrm{GHz}$ are 2, 1.4, 1.2 respectively. The designed antenna exhibits wideband frequencies with VSWR $<2.2$. 
1.RMPA Array

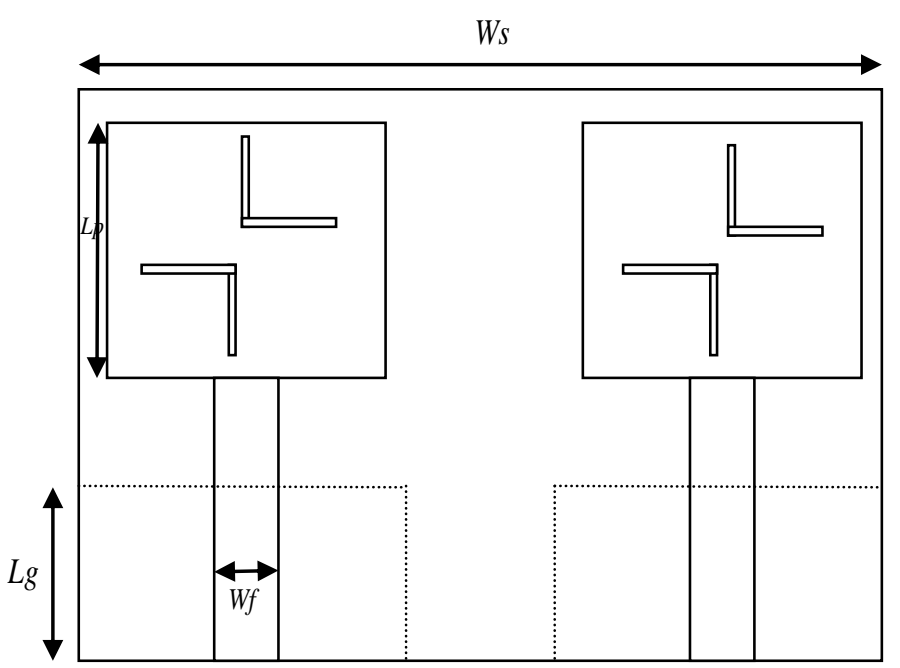

Fig7: RMPA Array

\section{Numerical Results:}

For microstrip patch antenna percentage bandwidth is 54\%.After employing the slotting technique percentage bandwidth increased to $91 \%$ with respect to the centre frequency $3.7 \mathrm{GHz}$.the gain of the antenna with two slots is $2.5 \mathrm{~dB}$ where as for antenna array it is increased to $10 \mathrm{~dB}$. The tabular form for VSWR and return loss for both antennas with and without slot is given below.

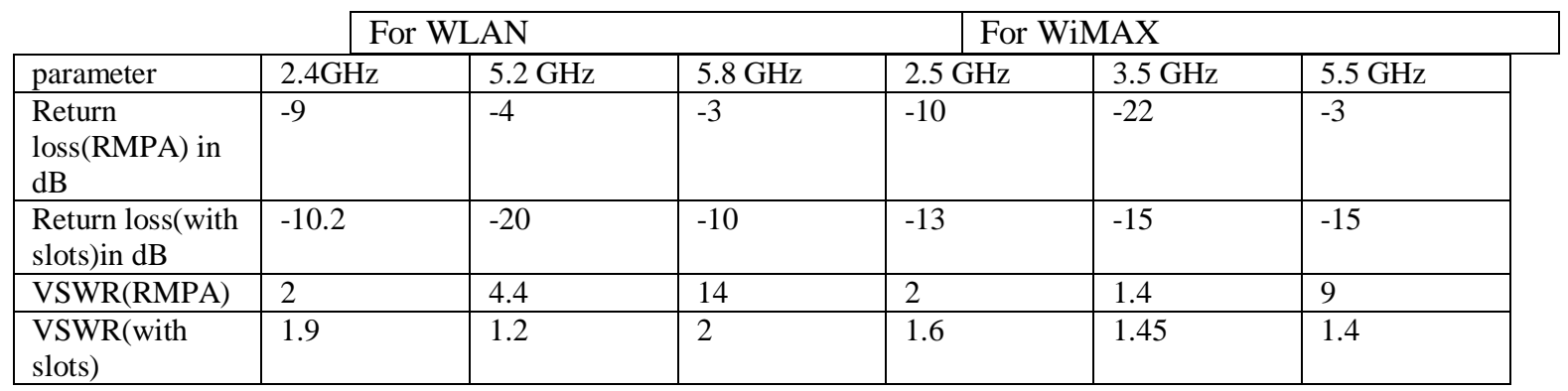

Table1: Comparison table for antenna with and without slot

\section{Conclusion}

The rectangular microstrip patch antenna with, without slots and array is designed and simulated. We conclude that by employing two different slots, a good bandwidth and a perfect impedance match can be obtained. Further, the design resulted in smaller size antenna with good omnidirectional radiation characteristics for all operating frequencies. The measured and simulated results of return loss, VSWR have been presented and discussed. Obtained results show that the antenna operates effectively in all the required WLAN and WiMAX communication bands.

\section{References}

[1] Balanis CA. Antenna theory, analysis and design. New York: John Wiley \& Sons, Inc.; 1997.

[2] Lee Cheng-Tse, Wong Kin-Lu. Uniplanar printed coupled-fed PIFA with a band-notching slit for WLAN/WiMAX operation in the laptop computer. IEEE Trans Antennas Propagat 2009;57(4).

[3] Jan Jen-Yea, Wang Liang-Chin. Printed wideband rhombus slot antenna with a pair of parasitic strips for multiband applications. IEEE Trans Antennas Propagat 2009;57(4).

[4] Chu Qing-Xin, Yang Ying-Ying. A compact ultrawideband antenna with 3.4/5.5 GHz dual band-notched characteristics. IEEE Trans Antennas Propagat 2008;56(124).

[5] Kuo Yen-Liang, Wong Kin-Lu. Printed double-T monopole antenna for 2.4/5.2 GHz dual-band WLAN operations. IEEE Trans Antenna Wireless Propagat 2003;51(9).

[6] Chen Horng-Dean, Chen Jin-Sen, Cheng Yuan-Tung. Modified inverted-L monopole antenna for 2.4-5 GHz dual-band operations. Electron Lett 2003;39(22).

[7] Bhatti Rashid Ahmad, Im Yun-Taek, Park Seong-Ook. Compact PIFA for mobile terminals supporting multiple cellular and noncellular standards. IEEE Trans Antenna Wireless Propagat 2003;57(9). 